\title{
INOVAÇÃO EM ESCOLAS RURAIS: O CASO SERTA (PERNAMBUCO - BRASIL)
}

Elie Ghanem*

\begin{abstract}
RESUMO
Este artigo aborda a origem da inovação educacional na atuação de uma ONG com escolas públicas de educação básica, em municípios de Pernambuco, Brasil. O objetivo da pesquisa foi detectar a presença ou não de alguns fatores na gênese da experiência investigada. Trata-se de um estudo de caso para o qual foi feito o exame de publicações e realizadas entrevistas semiestruturadas com dirigentes e agentes da ONG, assim como com docentes de escolas rurais e gestores de secretarias municipais de educação. Conclui que fatores salientes na geração da inovação são o tempo de experiência profissional de educadores(as), a estabilidade de sua equipe, o nível de qualificação e a atuação mobilizadora de líderes da ONG.
\end{abstract}

Palavras-chave: Inovação educacional. Reforma educacional. Escola rural. Pernambuco.

\section{ABSTRACT}

\section{INNOVATION IN RURAL SCHOOLS: THE CASE OF SERTA (PERNAMBUCO - BRAZIL)}

This article dicusses the origin of educational innovation in a NGO's work with basic public schools in municipalities of Pernambuco, Brazil. The research aimed to detect the presence or absence of certain factors in the genesis of the experience investigated. It is a case study for which publications were examinated and semi structured enterviews were conducted with the NGOs' heads and agents, as well as with rural teachers and managers in municipal secretaries of education. It concludes that salient factors in generating innovation are the length of the educator's professional experience, the stability of their staff, the level of qualification and the mobilizing role of leaders of NGOs.

Keywords: Educational innovation. Educational reform. Rural schools. Pernambuco.

\section{RESUMEN}

\section{INNOVACION EN ESCUELAS RURALES: EL CASO SERTA (PERNAMBUCO - BRASIL)}

Este artículo aborda el origen de la innovación educativa en la acción de una ONG con las escuelas públicas de educación básica en municipios de Pernambuco, Brasil. El objetivo de la investigación fue detectar la presencia o ausencia de algunos factores en la génesis de la experiencia investigada. Se trata de un estudio de caso para el que se hizo un examen de publicaciones y se llevó a cabo entrevistas semi-estructuradas con

* Doutor em Educação pela Universidade de São Paulo (USP). Professor de Sociologia na Faculdade de Educação da Universidade de São Paulo (USP). elie@usp.br 
líderes y agentes de la $\mathrm{ONG}$, así como con maestros de escuelas rurales y directivos de secretarias municipales de educación. Concluye que los factores más destacados en la generación de innovación son el tiempo de experiencia profesional de los educadores, la estabilidad de su equipo, el nivel de cualificación y la actuación movilizadora de los líderes de la ONG.

Palabras clave: Innovación educativa. Reforma educativa. Escuela rural. Pernambuco.

\section{Introdução}

Já nos anos 1960, a inovação educacional experimentada atomizadamente décadas antes despontou como uma orientação muito difundida. Isto foi assinalado por Parkerson e Parkerson (2014) quanto aos Estados Unidos, mas também nos demais países que inicialmente compuseram a Organização para a Cooperação e Desenvolvimento Econômico (OCDE), em cuja estrutura se integrou o Centre for Educational Research and Innovation (CERI) (CONSELHO DE REITORES DAS UNIVERSIDADES BRASILEIRAS, 1972). No Brasil, contudo, esse direcionamento vem ganhando maior atenção muito recentemente. O Ministério da Educação lançou o programa para "criar as bases para uma política pública de fomento à inovação e à criatividade na educação básica" e um de seus objetivos específicos é conhecer "a extensão, a distribuição geográfica e o perfil da inovação e criatividade na educação básica brasileira" (BRASIL, 2015). De acordo com o Ministério, tecnologias de comunicação que facilitam o autoaprendizado, relações de trabalho menos regulamentadas e carreiras imprevisíveis, além de exigências éticas prudentes em relação ao planeta, demandam uma educação que não se reduza à escola nem ao seu modelo convencional. Contudo, ao lado de não haver informação suficiente sobre o panorama das práticas inovadoras em andamento, são grandes os desafios para sua propagação, pois não há conhecimento a respeito dos fatores presentes no surgimento de tais práticas.

A pesquisa da qual se originou este $\operatorname{artigo~}^{1}$ oferece alguma contribuição nesse aspecto porque esteve centrada no seguinte problema: que fatores se conjugam na geração de ações de inovação educacional? A pesquisa enfocou a inovação

1 Realizada com apoio da Fapesp (Fundação de Amparo à Pesquisa do Estado de São Paulo). educacional como práticas independentes da atuação reformadora de governantes, ao passo que muitas outras obras trataram de inovações como reformas educacionais - como, por exemplo, Tyack e Cuban (1995), Farrell (2001a, 2001b), Didaskalou (2002), Lawton (2001), Glória e Mafra (2004), Levin (2008) e Tura e Marcondes (2008) - e procuraram as razões pelas quais as reformas não conseguiram alterar as práticas correntes, ou seja, não inovaram segundo as intenções dos reformadores.

Inovação, mudança, transformação e outros termos aproximados são utilizados geralmente como sinônimos nas abordagens da inovação educacional. Ganham o sentido de ações com o objetivo de alterar práticas educacionais. Até obras destacadas, tais como Huberman (1976), procedem da mesma maneira, apesar de fazerem diferenciações quanto à escala em que o fenômeno ocorre. Referem-se à possibilidade de a mudança ou inovação terem lugar em uma ou em poucas escolas, assim como chegarem a atingir o conjunto de escolas de uma província ou estado, de uma região ou de um país. Quando se voltam para esta maior escala, as pesquisas muitas vezes denominam seu objeto de reforma educacional, a exemplo de Craig (2001a, 2001b), Hatch (2001) e Drake e Sherin (2006).

Algumas vezes, a mudança planejada é vista como mudança radical de larga escala; outras vezes, como pequenas mudanças incrementais ou como combinações de mudanças incrementais com uma mudança radical em longos períodos de equilíbrio. As proveitosas análises de Parsons e Fidler (2005) mostraram isto. Sem prejuízo do reconhecimento deste tipo de variação, utilizo aqui uma nomenclatura que se apoia na análise que Torres (2000) fez das relações entre reformadores e docentes, cujas características obstam a mudança educacional. 
Opto por diferenciar mudança educacional de reforma educacional e de inovação educacional. Nesta nomenclatura, a expressão mudança educacional diz respeito a uma mudança sistêmica, equivalente à mudança radical de grande escala. A mudança educacional, desta forma, constitui uma lógica própria, dentro da qual convergem práticas que originalmente obedecem a duas outras orientações: a da lógica da inovação educacional e a da lógica da reforma educacional.

Reservo a expressão inovação educacional para a perspectiva seguida por práticas que se originam tipicamente na base de sistemas escolares, ou seja, em estabelecimentos individualmente considerados ou em organizações de alcance local, geralmente conhecidas como associações comunitárias. Deve-se pensar que as práticas de inovação se caracterizam principalmente por serem atividades diferentes daquelas que respeitam um costume em um determinado lugar e grupo social. São inovadoras por oposição a este costume e não devido a algum ineditismo. A tendência da inovação educacional, portanto, é muito mais endógena que exógena, constituindo-se por práticas baseadas em pronunciado voluntarismo de educadores(as), isoladas, fragmentadas, descontínuas no tempo e com ações de baixa visibilidade.

As práticas não criadas por agentes que as executam diretamente seguem a lógica da reforma educacional e são designadas com esta expressão. São geralmente prescritas por autoridades estatais do poder executivo e autoridades acadêmicas das universidades, de modo que sua tendência é muito mais exógena que endógena, seu caráter é normativo e impositivo. Entretanto, contam com recursos orçamentários do poder público que lhes conferem sustentabilidade, uma ampla abrangência e uma visibilidade, mas também um formato homogêneo.

Certamente as alterações pretendidas ou que venham a ocorrer em práticas educacionais também estão sujeitas a juízos de valor, mas convém atentar para a ressalva de Craft (2003) para que não sejam consideradas boas em si mesmas. Assim sendo, a pesquisa das práticas educacionais abarcadas tanto pela reforma quanto pela inovação não deve atribuir a estas necessariamente um valor positivo ou negativo a priori.

\section{Opções metodológicas}

A pesquisa que apresento neste texto, em que pese serem muitos os aspectos relevantes para compreender as ações que obedecem cada uma das lógicas, focalizou fatores que estariam na gênese das experiências inovadoras. Pela própria definição de inovação que adotei, ficaram descartadas a atuação dos níveis hierárquicos mais elevados da administração dos sistemas escolares ou dos aparatos estatais de maneira geral. Em consequência, a pesquisa se dedicou à hipótese de que os fatores salientes que se conjugam são a experiência profissional de docentes, a estabilidade de corpos docentes, a atuação mobilizadora de diretores(as) de estabelecimentos e o grau de qualificação profissional de integrantes de organizações comunitárias. Realizei o estudo de quatro casos de inovação para examinar a veracidade desta hipótese. São casos de trabalhos de ONGs (Organizações Não Governamentais) nos estados brasileiros de Amazonas, Ceará, Rio de Janeiro e Pernambuco. Os resultados deste último são descritos neste artigo.

Foram feitas adequações nos fatores priorizados na hipótese, uma vez que se tratava de ONGs e não de escolas comuns. O tempo de experiência de docentes na profissão cedeu lugar ao tempo dos(as) agentes educadores(as) das ONGs, assim como a estabilidade destes(as) na função foi considerada como equivalente à estabilidade de corpos docentes em escolas. A atuação mobilizadora de líderes das ONGs ficou equiparada à de diretores(as) de estabelecimentos. Finalmente, o nível de qualificação profissional de líderes das ONGs substituiu o nível de líderes de associações comunitárias.

As informações utilizadas foram colhidas ao longo de 2010, em publicações e em visitas a cinco municípios da Zona da Mata (Gloria do Goitá), do Agreste (Riacho das Almas e Arcoverde) e do Sertão (Tuparetama e São José do Egito), com entrevistas semiestruturadas realizadas com dirigentes e agentes educacionais do Serviço de Tecnologia Alternativa (Serta), docentes das escolas locais, dirigentes e técnicos de secretarias municipais de educação. 


\section{Resultados}

\section{O Serta e a proposta educacional de apoio ao desenvolvimento sustentável (Peads)}

Voltado para o desenvolvimento local por meio do fortalecimento da agricultura familiar, o Serta é uma ONG fundada em 1989, que se dedica a formar jovens, educadores(as) e produtores(as) familiares. Dez anos depois, instalou-se em Glória do Goitá, Zona da Mata de Pernambuco. No ano seguinte, formou a primeira turma de Agentes de Desenvolvimento Local, embrião do que seria um curso técnico reconhecido oficialmente, cuja primeira turma é de 2006. Em 2004, iniciou outra sede no Sertão, em Ibimirim. Em 2010, contava com nove projetos apoiados por ministérios, por uma grande empresa, por uma fundação privada de atuação internacional e pelo Fundo das Nações Unidas para a Infância (Unicef).

Sua abrangência se estende por dezenas de municípios de Pernambuco e pelos estados vizinhos da Paraíba e de Sergipe, capacitando jovens como agentes da reforma agrária, prestando assistência técnica para ampliar a gestão da terra no combate à pobreza, estruturando postos de vendas e organizando feiras de agricultura orgânica. Orienta cerca de 70 escolas rurais comuns de 15 municípios para uma educação a partir da compreensão das crianças e jovens sobre suas potencialidades e da região como espaço de qualidade de vida, animando também o intercâmbio de expressões teatrais e musicais.

A ONG foi constituída por um grupo de agricultores(as), técnicos(as) e educadores(as) voltados para a produtividade e o equilíbrio ambiental da agricultura familiar. Formalmente, sua missão é formar jovens, educadores(as) e produtores(as) para promoverem o desenvolvimento sustentável do campo (SERVIÇO DE TECNOLOGIA ALTERNATIVA, 2011). Suas duas sedes são também escolas técnicas de nível médio em agroecologia.

Desde os anos 1990, veio sendo elaborada e experimentada a Proposta Educacional de Apoio ao Desenvolvimento Sustentável (Peads) em escolas de nível fundamental ou médio e em variados programas de formação de agentes. Partes da
Peads foram integradas às Diretrizes Operacionais para a Educação Básica nas Escolas do Campo, do Ministério da Educação (BRASIL, 2002). A perspectiva da Peads é de mobilização social e construção de bases tecnológicas para o desenvolvimento sustentável. Seu processo implica investigar as atividades econômicas e as variáveis que inibem o desenvolvimento dos territórios em que jovens e educadores(as) atuam e vivem (MORAES, 2003). Assim, alunos(as) das escolas comuns são postos(as) na condição de produtores(as) de conhecimento em apoio a processos de desenvolvimento local. As famílias são convidadas a participar, especialmente com seus saberes tradicionais sobre a atividade agrícola. Em uma etapa é feito o levantamento de informações sobre aspectos da propriedade rural, em seguida, estas são analisadas e sistematizadas para, na terceira etapa, os resultados serem compartilhados. A quarta etapa é centrada na avaliação da experiência.

Nos seus primórdios, o Serta realizava mutirões, que implicavam aproximar-se dos(as) agricultores(as), reunir-se em suas casas e trabalhar em grupos. Este contato acentuou a percepção da distância mantida pela escola comum em relação ao caráter agrário da realidade daquelas pessoas. Uma figura central na liderança desse processo, desde o início, é Abdalaziz de Moura Xavier de Moraes, conhecido como Moura, um dos fundadores do Serta e um dos principais formuladores da Peads. Ele se considerava ciente do notório "caráter elitista da escola" no Brasil, mas sua abordagem, baseada na teologia da libertação, valorizando muito a ideia de comunidade, levou-o a supor que a escola deveria ser da comunidade. Moura procurou as professoras e jovens das escolas rurais para compartilhar a indagação sobre as razões de a escola seguir uma dinâmica alheia à realidade local.

\section{Entre "trabalho de base" e "políticas públicas"}

Ao longo dos anos 1990, o Serta esteve a ponto de encerrar as atividades por falta de recursos. Durante este período, manteve os mutirões, mas gradativamente modificou seu direcionamento, passando ao que se entendia como "voltar-se para as políticas públicas". Uma reorientação pela qual 
passaram muitas ONGs no Brasil, deslocando-se da concentração no chamado "trabalho de base". Órgãos públicos, assim como as agências de cooperação que financiavam as ONGs, começaram a colocar demandas por elaboração e execução de políticas. Isto significou um relacionamento de cooperação com o Estado, que inexistia até então.

Ao mesmo tempo, órgãos públicos e agências de cooperação pressionavam as ONGs tanto para acentuar sua própria especialização, quanto para diversificar suas frentes de atuação, envolvendo escolas, jovens, agricultura e políticas públicas. Moura também teve um papel destacado para que se evitasse o predomínio de apenas um foco, assim como a fragmentação das ações na linha de atuação do Serta.

É excepcional essa aproximação da ONG com a área da escola pública básica, considerando a inspiração católica de Moura. De modo geral, a igreja Católica se manteve distante deste universo, mesmo nos anos 1970 e 1980, quando a teologia da libertação e a sua opção preferencial pelos pobres exerceu uma forte influência no Brasil e em outros países da América Latina. Em outro lugar (GHANEM JÚNIOR, 1992) mostrei como agentes do movimento por moradia, na periferia de São Paulo, formados em sua maioria como militantes em comunidades eclesiais de base católicas, com intensa atuação política, desconheciam absolutamente a dinâmica e os mecanismos colegiados de gestão de escolas públicas de nível básico em seus territórios. Interpretei esta discrepância como decorrente de duas forças. Em parte, a escola básica é uma organização burocrática mesclada com a persistência de práticas próprias de um poder patrimonialista, o que torna cada estabelecimento impermeável às pressões exercidas pelos níveis superiores da hierarquia administrativa estatal e mais ainda às pressões de baixo, ou seja, da população usuária dos serviços escolares. De outra parte, o despreparo de agentes católicos se devia ao alheamento da sua igreja em relação ao mundo da escolarização pública, pragmaticamente tomado apenas como lugar para exercer ensino religioso ou como fonte de recursos a serem disputados para financiar suas obras escolares privadas.

Contudo, além de mover-se em direção à escola pública, Moura esteve à frente da resistência às exigências de agências de cooperação, que, por priorizarem atuar com jovens, não queriam que o Serta abarcasse as escolas de ensino fundamental, as quais, em sua maioria, lidam com crianças. Tendo passado por um período de grandes privações durante os anos 1990, o Serta começou, em 2000, a participar de uma coalizão para um projeto de quatro anos (Aliança com o Adolescente para o Desenvolvimento Sustentável do Nordeste) com parceiros dotados de muitos recursos financeiros: Instituto Ayrton Senna, Fundação Kellogg, Fundação Odebrecht e Banco Nacional de Desenvolvimento Econômico e Social (BNDES). Seria conveniente acatar as restrições daqueles parceiros para assegurar o financiamento de atividades. Para se ter uma ideia da magnitude dos recursos disponíveis, note-se que a Odebrecht é uma grande organização de negócios diversificados, com sede na Bahia, outro estado do Nordeste. Seu presidente estava disposto a construir um campo de pouso no terreno do Serta, para visitar as atividades do projeto em seu próprio avião. Só não concretizou sua intenção porque a prefeita do município não permitiu, já que ela preferia a construção de uma estrada de rodagem.

A Aliança com o Adolescente pretendia a formação de jovens do campo para que estes(as) voltassem às suas propriedades com qualificação empreendedora e renovada, com outra mentalidade, conhecendo informática e entendendo de políticas públicas. Sua intenção era que aqueles(as) jovens mudassem suas circunstâncias, tanto em suas famílias quanto no uso de tecnologias de trabalho, quanto ainda no ambiente político de sua vida adulta. Moura opôs-se decididamente à Fundação Odebrecht, que não admitia financiar o projeto sequer se este envolvesse ações com escolas porque não era sua prioridade. Aceitaria, no máximo, incluir escolas de nível médio. Por fim, após duras negociações, as escolas rurais de ensino fundamental foram incluídas.

A presença do Serta na região do Sertão foi demandada por agências de cooperação que priorizavam atuar com jovens que viviam na área de plantio clandestino de maconha. Reconheceu-se, para isto, a necessidade de envolver as escolas rurais, tema de especialidade do Serta. Esta demanda se somou à aspiração de "transformar a Peads em 
uma política pública", abrindo caminho a uma pedagogia adequada para as escolas do campo. Estritamente, "transformar em política pública" significa a prefeitura aceitar que "a metodologia" adotada na experiência limitada oriente o projeto pedagógico do conjunto de escolas sob sua jurisdição e o plano municipal de educação.

A crescente ampliação da abrangência do trabalho do Serta fez com que as condições de praticar a Peads se modificassem muito. Inicialmente, era uma prática centrada em relações interpessoais mantidas principalmente por Moura com cada professora. Transformou-se em formação de docentes em bloco, com atividades simultâneas e prazos fixados. Estas outras condições impuseram uma tensão da adoção de rotinas tendendo a programas escolares (geralmente denominados currículo) frente à orientação aberta, baseada num diálogo sem caminho previamente estabelecido.

\section{Confiança e espontaneidade}

Diferentes depoimentos que obtive convergiram quanto à posição central ocupada por Moura e quanto ao papel de sua contribuição intelectual ao caráter inovador do Serta. Um dos traços ressaltados em sua conduta foi a atitude de confiança nas pessoas, mesmo quando elas não apresentavam capacidade para realizar as tarefas propostas. Em consequência, enquanto algumas não se desenvolviam, outras se confrontavam com seus limites e os rompiam. A propósito, segundo a declaração de uma integrante de seu corpo dirigente, a pedagogia do Serta é composta, antes de tudo, pela relação de confiança e pela espontaneidade. Ela acredita que a escola normalmente faz com que $o$ (a) jovem brasileiro(a) se feche e procure não se mostrar, mas que as relações de confiança no Serta suplantavam esta atitude. Seguindo também uma forma muito espontânea de se trabalhar, não havia currículo previamente estabelecido. Confrontada a esta tendência, emergiu como dificuldade a demanda por materiais instrucionais para uso do magistério quando a prática da Peads deixou de ser experimental, passou a ser rotineira, e a formação tornou-se massiva. Entre os agentes do Serta, havia quem entendesse que os(as) professores(as) necessitavam de "material de apoio" (cadernos, fichas) para não se verem, a cada ano, repetindo as atividades propostas.

Essa conduta muito livre se chocava com o controle extremo típico de órgãos administrativos como as secretarias de educação dos municípios, de cuja colaboração o Serta necessitava para fazer suas atividades de formação, fosse com jovens, fosse com professores(as) das escolas municipais (por exemplo, para contar com meios de transporte para as pessoas participantes). Esta polarização se expressava também no debate interno do Serta, não apenas a respeito de se adotar ou não roteiros de atividades de formação, mas também de realizá-las em dias considerados oficialmente letivos, quando os(as) professores(as) normalmente estariam com suas turmas. A lei exige um mínimo de 200 dias letivos por ano, mas a definição de dia letivo apenas obedece a um costume pelo qual se considera letivo o dia em que cada docente está em atividades de ensino diretamente com suas turmas. Ou seja, para participarem de atividades de formação em dias letivos, suas turmas não poderiam comparecer às escolas e estar nas aulas regulares.

\section{Formação de docentes}

As escolas rurais são geralmente pequenas e têm somente entre uma e três turmas. Também aí a maioria do magistério é feminina, tem poucos anos de estudos e muitas professoras são leigas (sem formação específica para trabalharem como docentes). Estas características foram apontadas por várias pessoas que entrevistei, tanto do Serta quanto de secretarias municipais de educação. Um dos depoimentos chegou a indicar que os esforços de formação de docentes são desperdiçados porque se endereçam a pessoas semianalfabetas, as quais, nesta condição, são introvertidas, calam-se e não perguntam sobre nada. Ao mesmo tempo, a busca de aperfeiçoamento profissional por uma parte dos(as) professores(as) muitas vezes é mal vista pelos(as) próprios(as) colegas e combatida como uma arrogante atitude de "querer ser melhor que as outras".

Não obstante, docentes de vários municípios contaram com formação pelo Serta e os depoimentos que obtive indicaram que muitos(as) passaram a manter uma relação positiva com seus(suas) 
alunos(as) e deram continuidade a seus próprios estudos, inclusive em pós-graduação. Muitos(as) elevaram sua qualificação a partir do contato com o Serta. Um marco importante foi no município de Vicência, de onde quinze professoras das que contaram com formação pelo Serta passaram a disseminar a Peads em outros municípios. Passaram de professoras rurais a formadoras de professoras rurais.

\section{Relação com as prefeituras}

O Serta chegou diretamente às professoras de muitas escolas. Isto é geralmente algo que depende da colaboração de outros escalões do poder. Para ter acesso permitido a quem trabalha nas escolas, é preciso contar com certa disposição política de níveis superiores de uma hierarquia administrativa que inclui o(a) prefeito(a), o(a) secretário(a) municipal de educação, algum órgão intermediário entre este(a) e a escola, ou mesmo o(a) diretor(a) do estabelecimento escolar. Além disto, as escolas do campo são isoladas em diversos aspectos e, por isto, também é comum que a designação de docentes para estas escolas seja vista como um castigo aplicado a quem não faz parte do grupo político que comanda a prefeitura.

Foi também em Vicência que começaram a se combinar circunstâncias favoráveis para uma profícua experiência inicial de colaboração entre o Serta e o poder municipal. Vicência tem cerca de 28 mil habitantes, economia dominada pela monocultura de cana-de-açúcar e muita pobreza. Contudo, a prefeita daquele município mostrou uma sensibilidade especial com a proposta voltada para a ligação entre a educação nas escolas rurais e a agricultura familiar. Diferenciou-se também porque, como chefe do poder executivo, envolveu-se diretamente em uma área geralmente restrita à pasta municipal da educação. Esta, por sua vez, mesmo com alterações recentes encorajadas pela União Nacional de Dirigentes Municipais de Educação (Undime), comumente é ocupada por pessoas cujo único atributo distintivo é serem esposas de prefeitos. Muitos governos municipais, por seu turno, são controlados por poucas famílias proeminentes que se alternam nas prefeituras, mesmo nos municípios de maior porte. Isto confere uma continuidade impressionante dos grupos no poder. Por exemplo, a secretária de educação do município de Riacho das Almas, que entrevistei, já ocupava este posto fazia quase 30 anos.

A prefeita de Vicência mostrou grande envolvimento pessoal. Assistia palestras inteiras de especialistas do Serta na Câmara de Vereadores, assim como chegou a participar, com todas as professoras municipais de sua cidade, de jornadas de estudo na Universidade Federal, na capital, sobre a pedagogia de Paulo Freire. No governo daquela prefeita, todas as professoras municipais passaram a dar continuidade aos seus próprios estudos em nível superior.

Em muitos municípios, a secretaria da educação não tem corpos técnicos e o staff praticamente se resume à pessoa que ocupa o posto. Sendo pequenas, às vezes as escolas rurais contam só com uma professora, talvez uma merendeira e alguém em uma função administrativa de escrituração. São raras as que incluem diretor(a), cargo de importância proporcional ao tamanho das escolas. Deste modo, acertos feitos com ocupantes da pasta municipal de educação são mais decisivos para conseguir realizar diretamente atividades com docentes. A tendência dessas autoridades foi de consentir que o Serta atuasse junto a docentes das escolas municipais. A oferta de formação de docentes tinha grande aceitação por parte das autoridades pelo fato de ser gratuita para a prefeitura. Em muitos lugares, era a primeira vez que docentes recebiam convite para participar de formação em serviço.

A linha seguida pela Peads intencionalmente promove corresponsabilidade e incrementa a ação política de docentes, de alunos(as) e de seus familiares para mudar as formas de produção econômica e as circunstâncias que levam à sua atrofia. Alguns prefeitos rechaçam este processo devido aos questionamentos que daí emergem. Outros lugares têm desdobramentos construtivos, como o município de Lagoa de Quitaenga, em que a secretária da educação apoiou o trabalho, manteve autonomia frente ao prefeito, criou uma função de coordenação em cada escola do campo e um serviço de supervisão e de formação para o conjunto.

Outros prefeitos se aliam à proposta porque inclui “devoluções", ou seja, apresentações públicas de informações sistematizadas em que estudantes 
caracterizam os imóveis rurais, as edificações, as migrações, os rebanhos, a variedade da vegetação etc. As "devoluções" reúnem as comunidades, e alguns prefeitos procuram capitalizar estas oportunidades como apoio eleitoral.

Quando a crítica parece mais ameaçadora do que os dividendos eleitorais, surgem os embaraços ao trabalho. A proposta é de atividades educacionais coletivas de pesquisa, por turma, por escola, esta também vista como uma comunidade da qual as famílias dos(as) alunos(as) fazem parte. No município de Pombos, por exemplo, a capacitação passou a incomodar por levar ao aumento do nível de exigência. Por isto, a secretaria da educação passou a boicotar os encontros de capacitação, suspendendo-os muito próximo das datas marcadas. No primeiro governo de um dos prefeitos de Pombos, ele comparecia a todos os momentos de "devolução" dos dados às comunidades. No segundo mandato, o prefeito nomeou um preposto político para a secretaria da educação, que passou a prejudicar veladamente o trabalho com sucessivos adiamentos das atividades. No município de Feira Nova, devido à efervescente mobilização proporcionada pela Peads, o Serta foi afastado pela prefeitura e as escolas do campo foram abandonadas. A prefeita de Glória de Goitá, igualmente, em muito pouco tempo, desfez-se do Serta, que tem sede naquele município.

As relações de dominação no município foram destacadas por técnicos e dirigentes do Serta como obstáculos à implementação da Peads. Uma opressão ao mesmo tempo sutil e ferrenha, conforme declarou uma integrante do Serta: "Toda vez que a pedagogia cresce, ela esbarra num contexto de relações políticas". Segundo reiteraram vários agentes do Serta, prefeitos(as) querem obediência absoluta e há entre estes(as) quem recorra a ameaças de morte. A proposta do Serta abrange escolas, um elo importante naquela cadeia de dominação e, com a prática da Peads, surgem reivindicações de condições materiais também para as escolas.

Como disse uma dirigente do Serta, o âmago da pedagogia que Moura propõe é "de libertação", o que leva a confrontar a autoridade de quem controla a política municipal, na qual se apoiam os grupos de parlamentares do Congresso Nacional e o poder executivo federal. Este controle está assentado em uma rede clientelista. Se alguém sofre um acidente, mesmo que seja a poucos quilômetros da sede do município, precisará da ajuda privada de chefes políticos locais, que oferecem transporte. É muito comum cada vereador ter uma ambulância ou um ônibus para levar doentes para a Capital, numa ajuda que cria um laço de afetividade e uma dívida política. A Peads levava as pessoas a questionarem esta forma de exercício de poder e a se organizarem. Quando isto acontecia, o Serta perdia a colaboração das prefeituras.

\section{Os efeitos da Peads}

Não foram detectadas práticas inovadoras originadas no âmbito das escolas. Nenhum dos depoimentos colhidos confirmou haver docentes com iniciativa própria de fazer algo diferente em seu trabalho. Ao contrário, somente houve a indicação de que uma grande parte do magistério é "praticamente analfabeta" e se divide entre as pessoas que se identificam e as que não se identificam "com o aluno". Quer dizer, as primeiras se empenham muito em encontrar uma forma adequada de ensinar e em defender suas turmas da seletividade da escola. As outras são classificadas como aquelas que querem "deixar o tempo passar e ter o mínimo possível de trabalho".

A baixa qualificação do magistério é associada a uma percepção de que este se sente inseguro no exercício profissional, visto como altamente dependente do que se prescreve em livros didáticos, ao mesmo tempo em que tem que mostrar uma imagem de si como autoridade e fonte do conhecimento. Esta tensão se arrefece ou neutraliza porque a Peads aponta a perspectiva de que docentes e estudantes se coloquem na posição legítima de quem ignora e busca informação. Como disse uma dirigente do Serta, isto "liberta o professor" e, "quando os alunos chegam de casa com a pesquisa, o próprio professor se surpreende com as coisas que eles trouxeram".

Essas práticas motivaram docentes a adotar uma visão positiva da escola do campo, passando a preferir nesta permanecer em vez de trabalhar na cidade. Conforme vários depoimentos que obtive, $o$ professorado oferece demonstrações muito vivas de que "o que era castigo passou a ser um presente". 
Em parte porque as prefeituras raramente oferecem atividades de formação para o magistério, uma vez que seus custos costumam ser elevados devido à necessidade de transporte em longas distâncias. De outra parte, há forte envolvimento emocional durante os momentos de formação coordenados pelo Serta, nos quais as pessoas chegam a chorar.

\section{Líderes, agentes e equipes}

Uma dúzia de pessoas fazem parte da diretoria e do conselho fiscal do Serta. São profissionais de diversas áreas, com pelo menos cinco anos de experiência, e alguns se dedicam à ONG desde a sua fundação. Deste modo, tanto o tempo de experiência profissional quanto a estabilidade do núcleo dirigente e a qualificação das pessoas que o integram são muito pronunciadas. Em termos de atuação mobilizadora de líderes, esta é intrínseca aos propósitos do Serta e é efetiva, inclusive porque dela depende a obtenção de recursos para manter a organização. Os projetos do Serta se caracterizam por serem modalidades de orientação, por meio de consultoria ou atividades de formação, por parte de educadores(as) que também se formaram em agricultura familiar sustentável por meio do Serta e da Peads. Não são, portanto, iniciantes ou pessoas sem algum tipo de estudo especializado.

Exemplos de profissionais com esses traços são o educador e a educadora de grande dedicação ao Serta que me guiaram em visitas a escolas em São José do Egito, no Sertão, e em Riacho das Almas, no Agreste. Ambos com idade em torno de 30 anos, trabalharam como docentes em escolas rurais de nível fundamental. Afirmaram que as escolas do campo eram desprezadas também pelas pessoas do lugar, que preferiam ir para as escolas da cidade. A educadora já havia sido diretora de escola rural. Licenciou-se em matemática e foi aprovada em concurso público para docente. Trabalhou durante um ano como professora em uma escola rural e tornou-se diretora da escola. O cargo é comissionado e ela o preencheu por indicação do prefeito, também professor, que ela já conhecia. Decidiu visitar as casas das pessoas que viviam próximo à escola para fazer as matrículas e para conhecer as famílias. Procurou realizar ações de envolvimento para a reversão da imagem negativa que se fazia da escola. Foi procurando informação e ajuda para fazer seu trabalho como diretora que recebeu, emprestado de um professor, o livro de Moura sobre a Peads (MORAES, 2003). Com isto, ela procurou o Serta e logo se tornou formadora.

O destacado exemplo de longa experiência, alta qualificação e atuação mobilizadora é do próprio Moura. Ele estudou filosofia no Seminário Regional do Nordeste, concluiu teologia na Universidade Gregoriana de Roma, fez cursos de especialização no Instituto de Bossey, Universidade de Genebra e no Centro de Pesquisa de História das Religiões, em Bolonha. Durante sete anos, fez parte da coordenação do movimento de evangelização da Arquidiocese de Olinda e Recife e, nos sete anos seguintes, coordenou o projeto de organização comunitária da Diocese de Petrolina. Após deixar este projeto, passou cinco anos coordenando o Centro de Capacitação e Acompanhamento aos Projetos Alternativos da Seca. Então, em 1989, em colaboração com outros profissionais, fundou o Serta e o presidiu por diversos mandatos.

\section{Conclusão}

É amplamente conhecido que o modelo de educação escolar predominante se pauta pela pretensão de encarnar um caráter universal e pela missão de difundir saberes, o que habitualmente se chama de "transmitir conteúdos". Estes traços implicam o predomínio do alheamento em relação aos ambientes sociais particulares em que cada escola está instalada, assim como a concentração em informações muito típicas dos centros urbanos, lugares em que costumam viver as pessoas que influem na adoção daqueles "conteúdos". O caso do Serta e de sua proposta educacional para o desenvolvimento sustentável baseado na agricultura familiar foi apresentado como um caso de inovação educacional, uma vez que suas práticas se diferenciam das práticas educacionais usuais, principalmente por focalizarem a peculiaridade agrária em que vivem estudantes e suas famílias e por sua perspectiva centrada na produção coletiva de saberes por estudantes, familiares e docentes.

A hipótese em torno da qual se realizou a pesquisa ateve-se aos fatores presentes na gênese da inovação. Para examiná-la, coletei informação 
sobre os objetivos e as formas de realização das ações do Serta, bem como sobre tempo de experiência profissional dos(as) agentes educadores(as), estabilidade da equipe, qualificação e atuação mobilizadora de líderes. Educadores(as) iniciantes podem ser pessoas animadas de grande disposição para o trabalho e para a ampliação dos efeitos deste, enquanto profissionais mais experientes podem apresentar atitude mais segura e mais autoconfiança ao procurar seus objetivos. Por isto, a extensão da experiência profissional foi considerada um fator importante para a iniciativa em inovação educacional.

Quando integrantes de um grupo de profissionais de educação têm permanência, pode gerar e acumular consensos sobre o ambiente das suas práticas educacionais. Entretanto uma rotatividade maior pode enfraquecer compromissos com o grupo, favorecendo que indivíduos ou subgrupos sigam suas próprias perspectivas e procurem fazer experimentações. Por estas razões, entendi que a estabilidade das equipes é relevante para a inovação.

Iniciativas inovadoras entre educadores(as) também podem ser incentivadas pela atuação mobilizadora de líderes. Esta mesma atuação mobilizadora pode ocorrer ainda independente de um forte engajamento de educadores(as), constituindo-se em certo sentido como uma iniciativa própria. Por sua vez, um posicionamento crítico quanto à educação costumeira e uma dedicação a práticas diferenciadas podem decorrer do nível de qualificação profissional de líderes locais.

A hipótese levantada se confirmou, tendo-se verificado que todos aqueles fatores de inovação são salientes no caso Serta. A experiência profissional dos(as) agentes é expressiva, a equipe mostra grande estabilidade e os(as) líderes da ONG delineiam sua atuação exatamente por seu caráter mobilizador. A tudo isto se soma a longa experiência do dirigente e um nível elevado e incomum de escolaridade. Tais fatores se combinam e estão subjacentes a uma interação com escolas públicas por meio do contato direto com professores(as), implicando práticas com características e sentidos opostos aos costumes sedimentados em escolas do campo. São esforços sugestivos e promissores para tentativas de adequação da educação escolar de nível básico às condições tanto do magistério quanto das populações com as quais este trabalha.

\section{REFERÊNCIAS}

BRASIL. Ministério da Educação. Resolução CNE/CEB no 1, de 3 de abril de 2002. Institui diretrizes operacionais para educação básica nas escolas do campo. Brasília, DF, 2002. Disponível em: <http://portal.mec.gov.br/>. Acesso em: 05 nov. 2011.

Ministério da Educação. Chamada pública para escolas e organizações educativas. Brasília, DF, 2015. Disponível em: <http://criatividade.mec.gov.br/>. Acesso em: 29 out. 2015.

CRAFT, A. The limits to creativity in education: dilemmas for the educator. British Journal of Educational Studies, v. 51, n. 2, p. 113-127, jun. 2003.

CRAIG, C. J. No satisfaction: a case of "the monkey's paw", top-down school reform, and the conduit. Curriculum Inquiry, v. 31, n. 3, p. 341-350, 2001a.

. The relationship between and among teacher's narrative knowledge, communities of knowing, and school reform: a case of “the monkey's paw”. Curriculum Inquiry, v. 31, n. 3, p. 303-331, 2001 b.

DIDASKALOU, E. S. Current obstacles to change in Greek primary schools: implications for managing behavior problems. European Journal of Education, v. 37, n. 4, p. 473-482, 2002.

DRAKE, C.; SHERIN, M. Practicing change: curriculum adaptation and teacher narrative in the context of mathematics education reform. Curriculum Inquiry, v. 36, n. 2, p. 153-187, 2006.

FARRELL, J. P. Why is educational reform so difficult? Curriculum Inquiry, v. 30, n. 1, p. 83-103, $2001 \mathrm{a}$.

Can we really change the forms of formal schooling? And would it make a difference if we could? Curriculum Inquiry, v. 31, n. 4, p. 389-398, 2001 b.

GHANEM JÚNIOR, Elie George Guimarães. Lutas populares, gestão e qualidade da escola pública. 1992. $228 \mathrm{f}$. 
Dissertação (Mestrado em Educação) - Faculdade de Educação da Universidade de São Paulo (USP), São Paulo, 1992. GLÓRIA, D. M. A.; MAFRA, L. A. A prática da não-retenção escolar na narrativa de professores do ensino fundamental: dificuldades e avanços na busca do sucesso escolar. Educação e Pesquisa, v. 30, n. 2, p. 231-250, ago. 2004.

HATCH, T. The usual monkey business: a case of repetition and reform. A response to Cheryl Craig's "The relationships between and among teachers' narrative knowledge, communities of knowing, and school reform: a case of 'the monkey's paw”. Curriculum Inquiry, v. 31, n. 3, p. 333-340, 2001.

HUBERMAN, A. M. Como se realizam as mudanças em educação: subsídios para o estudo do problema da inovação. Tradução de Jamir Martins. São Paulo: Cultrix, 1976.

LAWTON, D. Book review “Images of educational Change”. British Journal of Educational Studies, v. 49, n. 4, p. 446-472, 2001.

LEVIN, B. How to change 5000 schools: a practical and positive approach for leading change at every level. Cambridge, MA: Harvard Education Press, 2008.

MORAES, A. M. X. Princípios e fundamentos da proposta educacional de apoio ao desenvolvimento sustentável. Recife: Serta, 2003.

PARKERSON, D., PARKERSON, J. A. Transitions in American education: a social history of teaching. New York: Routledge, 2014.

PARSONS, C.; FIDLER, B. A new theory of educational change - punctuated equilibrium: the case of the internationalization of higer education institutions. British Journal of Educational Studies, v. 53, n. 4, p. 447-465, Dec. 2005.

CONSELHO DE REITORES DAS UNIVERSIDADES BRASILEIRAS - CRUB. Seminário A administração da inovação no ensino. [S.1.], 1972.

SERVIÇO DE TECNOLOGIAALTERNATIVA - SERTA. Histórico. 2011. Disponível em: < http://www.serta.org. br/site/o-serta/historico/>. Acesso em: 05 nov. 2011.

TORRES, R. M. Reformadores y docentes: el cambio educativo atrapado entre dos logicas. In: CÁRDENAS, L., RODRIGUEZ CÉSPEDES, A., TORRES, R. M. EI maestro, protagonista del cambio educativo. Bogotá: Convenio Andrés Bello; Magisterio Nacional, 2000. p. 161-312.

TURA, M. L. R.; MARCONDES, M. I. Heterogeneidade, ciclos e a prática pedagógica. Revista Brasileira de Estudos Pedagógicos, v. 89, n. 222, 2008.

TYACK, D.; CUBAN, L. Tinkering toward utopia: a century of public school reform. Cambridge, Massachusetts: Harvard University Press, 1995. 